\title{
An implementation evaluation of a voluntary counselling and testing programme for the human immunodeficiency virus (HIV) and acquired immunodeficiency syndrome (AIDS)
}

\begin{abstract}
Authors:
Tarryn N. Anderson ${ }^{1}$

Joha Louw-Potgieter ${ }^{1}$

Affiliations:

${ }^{1}$ Section of Organisational

Psychology, University of

Cape Town, South Africa

Correspondence to:

Joha Louw-Potgieter

Email:

joha.louw-potgieter@uct. ac.za

Postal address:

Section of Organisational Psychology, University of Cape Town, Rondebosch 7701, South Africa

Dates:

Received: 18 Nov. 2010

Accepted: 28 Mar. 2012

Published: 17 July 2012

How to cite this article: Anderson, T.N., \& LouwPotgieter, J. (2012). An implementation evaluation of a voluntary counselling and testing programme for the human immunodeficiency virus (HIV) and acquired immunodeficiency syndrome (AIDS). SA Journal of Industrial Psychology/SA Tydskrif vir Bedryfsielkunde, 38(1), Art. \#944, 10 pages. http://dx.doi.org/10.4102/ sajip.v38i1.944
\end{abstract}

C 2012. The Authors. Licensee: AOSIS OpenJournals. This work is licensed under the Creative Commons Attribution License.
Orientation: Employee wellness programmes have become standard interventions in most organisations. In South Africa, these programmes invariably contain an element to address the problem of the human immunodeficiency virus (HIV) and acquired immunodeficiency syndrome (AIDS) in the workplace.

Research purpose: The purpose of this evaluation was to assess whether or not a Voluntary Counselling and Testing (VCT) programme for HIV and AIDS, at a South African university, was implemented as intended.

Motivation for the study: The evaluators were motivated to explore indications in the existing literature about these programmes that participants in VCT programmes are often not the intended target population who live a high risk lifestyle.

Research design, approach and method: A descriptive design was used to evaluate service utlisation, service delivery and organisational support. Questionnaire data from 285 respondents who participated in the programme and programme records supplied by the programme staff were consulted to answer the evaluation questions.

Main findings: The evaluation showed that the highest uptake for the programme occurred amongst female students. The low uptake amongst men was a concern. It was found that the programme was delivered as intended and that there were enough resources to implement it according to standards set.

Practical/managerial implications: The systematic report on the programme process provided the programme managers with practical suggestions for programme improvement.

Contribution/value-add: This was the first implementation evaluation of a VCT programme in a South African university context. As such it aimed to educate programme managers to think evaluatively about introducing new or continuing existing programmes.

\section{Introduction}

\section{Key focus of the study}

The main focus of this study was to assess whether or not a Voluntary Counselling and Testing (VCT) programme was implemented with fidelity in a university setting. The study focused on the following questions: who participated in the programme; how was the programme rolled out; and were there enough resources to implement the programme properly?

\section{Background to the study}

The rapid spread of the immunodeficiency virus (HIV) is one of the most serious health issues confronting both developed and developing countries worldwide. The acquired immunodeficiency syndrome (AIDS) pandemic in sub-Saharan Africa accounts for three-quarters of the worldwide HIV burden (Standton et al., 1998). Antiretroviral treatments have improved the quality of life for people living with HIV and AIDS, but there is currently no cure or vaccine available for them (Coetzee \& Patel, 2000). Prevention seems, therefore, the best way to reduce the spread of HIV and AIDS.

VCT is becoming increasingly recognised as a component of effective HIV prevention initiatives (Day et al., 2003; United Nations Population Fund [UNFPA], 2002). It provides important HIV-related information to individuals who may be at risk of contracting HIV. Furthermore, it provides treatment and support to those who are infected (Subramanian, Gupte, Mathai, 
Boopathi \& Dorairaj, 2008). VCT generally consists of three stages, namely, (1) pre-test counselling and assessment of risk, (2) a rapid test with same-day results and (3) posttest counselling. VCT is perceived by some researchers and medical practitioners as a milestone for the prevention of HIV and the provision of support for those living with HIV (Mabunda, 2004). However, specific implementation protocols need to be followed in order for this intervention to be effective (Bhagwanjee, Petersen, Akintola \& George, 2008; Mundy \& Dickinson, 2004).

Because of the high prevalence of HIV and AIDS amongst young people in South Africa most wellness programmes at universities contain a component about HIV and AIDS prevention. The Higher Education HIV and AIDS programme (HEAIDS), funded by the European Union, provides limited financial assistance to universities to help them upgrade their HIV and AIDS programmes. A university in the Western Cape has used this funding to implement a VCT programme. Although there are ample programme documents, no systematic evaluation of this programme has taken place.

This evaluation study seeks to determine whether or not the VCT programme at this university has been implemented according to its original plan. As an implementation evaluation the study contains the following steps:

- a detailed description of the programme plan

- a programme theory based on the programme activities as described

- a review of similar programmes or social science literature to test the plausibility of the programme theory

- an implementation evaluation consisting of questions based on the theory that relates to the target population, programme delivery and resources.

Each of these steps will be discussed below.

\section{Programme description}

The programme description was elicited by means of programme documents (Centre for Human Development, 2002; Coetzee \& Patel, 2000; Davidson, n.d.; Family Health International, 2003; Landon, 2007, 2008, 2009; Smuts, 2000). A draft of the description was submitted to the programme manager who verified it and gave permission for an implementation evaluation. Below is the detailed programme description.

The VCT programme under evaluation was developed by Dr Wendy Orr in 1995. Together with the Dean of Students, Dr Orr also developed an HIV and AIDS policy for the university which protects individual rights and encourages VCT. Dr Orr and Sister Knighton-Fitt developed the process of the VCT and a step-by-step plan for the pre- and post-test counselling sessions. The VCT programme has been running since 1995 and has been funded over the years by various benefactors.

The programme is available to all students and staff. It is operated from two sites on two different campuses. Major VCT drives take place twice a year in March and August at two sites. A mobile VCT bus, which moves between the university's campuses and provides services to participants on a walk-in basis, was introduced in 2008. In 20085209 students and staff members made use of the VCT service.

The high level goal of the programme is to 'reduce the spread of the HIV virus by altering the behaviours of people, particularly those who are infected and those who are at risk' (Coetzee \& Patel, 2000, p. 1). When implemented properly the programme aims to break the vicious circle of fear, stigma and denial' (Coetzee \& Patel, 2000, p. 1). These goals have been aligned with the university's HIV and AIDS policy and the Department of Health's (DOH) guidelines.

According to Coetzee and Patel (2000), the VCT programme consists of three activities. The first activity, pre-test counselling (15-25 minutes), introduces the participant to the VCT process. The goal of pre-test counselling is to determine the parameters of the session, describe the roles and responsibilities of the participant and counsellor and establish an agreement with the participant about the objectives of the session. This is followed by a risk assessment which aims to engage the participant in an initial exploration of his or her HIV risk behaviour. Once the counsellor has determined the participant's level of risk, appropriate prevention counselling will be provided. Prevention counselling is provided to identify the participant's attempts at reducing the risk of infection and his or her willingness to avoid risky behaviour. The counsellor will attempt to empower the participants to take action to protect themselves and others through skills building, role-plays, problem-solving, communication enhancement and condom skills. Thereafter, the participants receive counselling to gauge their willingness to be tested.

The second activity is the administration of the Rapid HIV test (Abbott Determine Antibody Test) (10-15 minutes) by a nurse or a medical practitioner. A small drop of blood is collected from the participant's finger into a test kit. A drop of buffer fluid is then added to the test kit. The test result is interpreted by observing the lines on the test kit (one line = negative; two lines = positive; no lines = indeterminate) . The test indicates $99.90 \%$ sensitivity and $99.75 \%$ specificity (Inverness Medical, 2009). After every 25 tests administered, a control test (Pareekshak Triline) is performed for the purpose of quality assurance.

Post-test counselling is the third activity (10-25 minutes). Participants receive their test results prior to counselling. For a negative result the counselling is focused on risk reduction in order to maintain this status. For a positive result, the counsellor provides clear information concerning the positive status and offers compassion and support. Counselling focuses on disclosure, partner referral, identification of support resources and medical follow-up. Finally, a risk reduction plan is negotiated with participants.

\section{Programme theory}

According to Bickman (1987, p. 5) programme theory is 'the construction of a plausible and sensible model of how a programme is supposed to work.' It focuses on the 
programme activities that are presumed to result in the intended outcomes (Donaldson, 2007; Donaldson \& Lipsey, 2006). Figure 1 illustrates the programme theory as set out in the programme description and conceptualised by the programme stakeholders.

From Figure 1 it is clear that the VCT programme aims to achieve short, medium and long term outcomes relating to the HIV and AIDS risk and status of an individual. The short term outcomes relate to knowledge acquisition of HIV and how it is transmitted. Medium term outcomes are associated with changing risky sexual behaviour to safer sex. The long term outcomes include the reduction in the number of HIV infections and transmission of the virus. It is understood that if VCT is able to achieve its short term, medium term and long term outcomes, it will ultimately be perceived as an effective tool that combats the HIV and AIDS pandemic.

\section{Plausibility of programme theory}

Once a programme theory has been elicited, the main question is: 'Will this programme work?' In order to find out whether or not the programme will deliver its intended outcomes, the programme theory is tested against evaluations of similar programmes or social science research results.

Numerous studies conducted in both developed and developing countries have concluded that VCT programmes can be valuable tools in the fight against HIV and AIDS (Hutchinson \& Mahlalela, 2006; Van de Perre, 2000). VCT is considered to be the most targeted and focused strategy to test people for HIV and manage the HIV pandemic (Njagi \& Maharaj, 2006; Richter, Van Rooyen, Solomon, Griesel \& Durrheim, 2001; Van Dyk \& Van Dyk, 2003). As a result VCT services have become fundamental components of many national AIDS programmes worldwide (Ginwalla et al., 2002; Wringe et al., 2008).

Studies conducted in the United States of America (USA) have shown that the acceptance of people living with HIV and AIDS was positively correlated with knowledge of the virus, its prevention and transmission (Okonkwo, Reich, Alabi, Umeike \& Nachman, 2007). The pre-test and posttest counselling provided during VCT aims to improve knowledge acquisition, reduce stigma, provide support for dealing with the infection and promote strategies for risk-reduction (Coetzee \& Patel, 2000; Ginwalla et al., 2002; McCauley, 2004; Wringe et al., 2008).

VCT services provide HIV positive individuals with access to appropriate medical treatment as well as ongoing social support services (Ginwalla et al., 2002; Inrungu, Varkey, Cha \& Patterson, 2008; Subramanian et al., 2008; Wringe et al., 2008). VCT also assists HIV positive individuals to plan for their future and prevent transmission of the virus to others (Irungu et al., 2008; Subramanian et al., 2008). Many medical practitioners and healthcare workers are acknowledging that VCT plays a significant role in the prevention, early diagnosis and reduction in the spread of HIV infection (Fako, 2006).

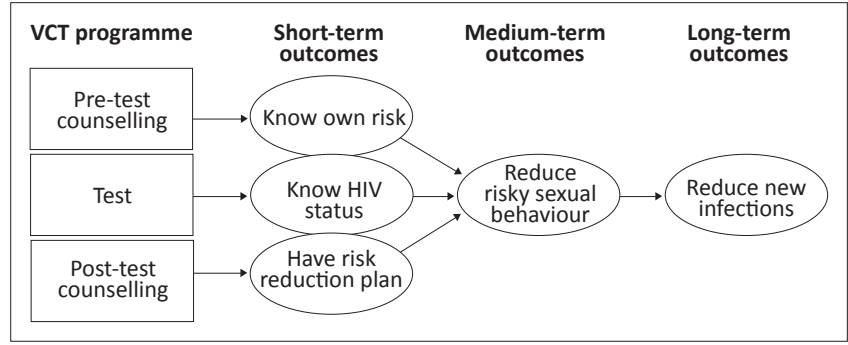

FIGURE 1: Programme theory for the VCT Programme.

Although some studies (Ho \& Loke, 2003; Okonkwo et al., 2007) have associated HIV knowledge with a willingness to test for HIV, Fako (2006) found that knowledge of HIV had no impact on a student's willingness to be tested for infection. Other researchers (Greiger \& Ponterotto, 1988; Hollar \& Snizer, 1996; Keeling, 1991; Lema, Katapa \& Musa, 2008) have reported that knowledge about HIV did not determine the adoption of precautionary measures against HIV. In fact, Hollar and Snizer found that students with good HIV knowledge were more likely to engage in risky sexual behaviour. These findings are in line with Fishbein and Azjen's (1980) theory of reasoned action which indicates that a change in attitude does not necessary result in a change in behaviour.

Young people are the most vulnerable and affected sector of the global population infected with HIV (UNAIDS, 2004). Individuals aged between 15 and 24 account for more than half of the HIV infections worldwide, with over $50 \%$ of adults acquiring the virus before they reach 25 years of age (Steinberg, Kinghorn, Sonderlud, Schierhout \& Conway, 2001). This situation is even more serious in developing countries where the HIV pandemic is most severe (UNAIDS, 2004). Young people are more susceptible to HIV infection and, thus, it is important that they are the focus of HIV and AIDS interventions such as VCT (Njagi \& Maharaj, 2006). Furthermore, it becomes necessary to know which factors influence VCT uptake amongst young people.

Levels of education, perception of HIV risk and the number of sexual partners are significantly related to whether or not an individual is willing to access VCT (Fako, 2006; Subramanian et al., 2008). Wringe et al. (2008) found that the desire for VCT was highest for individuals who are educated. However, desire itself did not necessarily lead to these individuals making use of VCT services, as VCT was perceived by them as specifically for individuals who were HIV positive.

Researchers (Bond, Lauby \& Batson, 2005; Bwambale, Ssali, Byaruhanga, Kalyango \& Karamagi, 2008; Fako, 2006; Pronyk et al., 2002; Subramanian et al., 2008) found that women were more willing to make use of VCT than men. Fako (2006) also found that urban students were more likely to access VCT services compared to students who came from rural towns or traditional villages.

Students who were not sexually active were twice as likely to test for HIV compared with those students who were sexually 
active (Fako, 2006). Hutchinson and Mahlalela (2006) found that having multiple sexual partners over a 12 month period did not positively correlate with the use of VCT services. This indicates that individuals who have a more risky lifestyle are perhaps not the ones making use of VCT services.

Subramanian et al. (2008) found that the most common reason cited for a participant's willingness to be tested was the fact that it was good to know one's status. Seventy five percent of participants who responded to a survey conducted by Irungu et al. (2008) believed that it was important to know their HIV status so that they could protect both themselves and their partners from infection.

Researchers (Bhagwanjee et al., 2008; Bond et al., 2005; Corbett et al., 2006; Hutchinson \& Mahlalela, 2006; Irungu et al., 2008) also found that convenient and accessible VCT services were positively correlated with an individual's willingness to be tested.

Despite the positive opinions of VCT there is concern that a considerable number of individuals who may be at risk of contracting HIV are not being tested (Peltzer, Nzewi \& Mohan, 2004). Thus it is necessary to understand the barriers to VCT uptake.

The fear of HIV related stigma, discrimination and disclosure of one's HIV status are perceived to be the three most prominent barriers to HIV testing (Bhagwanjee, et al., 2008; Fako, 2006; Hutchinson \& Mahlalela, 2006; Kachroo, 2006; Matovu \& Makumbi, 2007; Wringe et al., 2008). Many people are concerned about how their partners, families and communities will react to an HIV positive result (Irungu et al., 2008; Subramanian et al., 2008). Some even fear domestic violence, loss of social status, abandonment and rejection (Hutchinson \& Mahlalela, 2006; Irungu et al., 2008). Philips, Coates, Eversley and Catania (1995) found that participants, particularly women in committed relationships, Black people, and those in the lower income brackets, were only prepared to be tested for HIV if they could be convinced that nobody else would have access to their results. Concerns about confidentiality, a perceived lack of treatment available to those who test HIV positive, as well as the fear of testing positive, are further barriers preventing people from making use of VCT services (Bhagwanjee et al., 2008; Ginwalla et al., 2002; Matovu \& Makumbi, 2007; Wringe et al., 2008). Some individuals refuse to be tested on the grounds that they do not consider themselves to be at risk of infection, or as a result of negative attitudes towards VCT (Hutchinson \& Mahlalela, 2006; Matovu \& Makumbi, 2007; Peltzer, et al., 2004; Subramanian et al., 2008).

In summary, and based on the relevant literature, it could be said that VCT does effectively improve HIV knowledge and awareness specifically amongst educated, urban women who do not lead sexually risky life styles. However, whether or not VCT leads to a behaviour change and increases safe sexual practices is uncertain, and these remain issues on which researchers disagree. Therefore, it could be concluded that the progamme theory presented in Figure 1 is plausible to an extent. VCT programmes do seem to lead to increased awareness, knowledge about HIV and AIDS and knowledge about the transmission of the disease. Despite this, there is no conclusive evidence that VCT programmes lead to a behaviour change which would, in turn, lead to fewer infections.

\section{Evaluation questions}

This evaluation focused on the implementation of a VCT programme. According to Scheirer (1994) an implementation evaluation verifies what the programme is and whether it is delivered as planned to the intended recipients or not. In other words, an implementation evaluation investigates whether or not the programme is operating as it is intended to function (Chen, 2005). Usually programme implementation is assessed by means of service utilisation, service delivery and organisational support (Rossi, Lipsey \& Freeman, 2004).

In order to determine alignment of actual implementation with planned implementation, as set out in the programme description, the following evaluation questions were formulated.

\section{Service utilisation}

1. How many students or staff members made use of the VCT programme?

2. What were the demographic characteristics of the participants?

\section{Service delivery}

3. Where did the participants hear about the programme?

4. What was the actual sequence of programme activities and did all participants receive the activities in the same sequence?

5. Was the programme delivered in the same manner across all VCT sites in terms of the quality of the pre-test counselling, HIV-test and post-test counselling?

6. Were participants satisfied with the service they received from the VCT programme?

\section{Organisational support}

7. Was the VCT programme well organised with specific focus on the length of time participants waited to receive the results from their HIV test?

8. Were the participants receiving the dosage, type and quality of counselling as stipulated in the VCT programme protocol documentation?

\section{The potential value-add of the study}

Louw (in progress) has pointed out that programme feedback within South African organisations is often haphasard and unsystematic. Few managers can provide answers to the following questions about programmes: On what grounds 
was the programme introduced? On what evidence are decisions based to continue with the programme?

This is the first implementation evaluation of a VCT programme in the context of a South African university. It provides a clear process theory based on the participants, programme activities and resources. The main value that the evaluation will add is to educate programme managers to think evaluatively (Patton, 2008). When such evaluative thinking becomes part of organisational culture, the programme design is examined, outcomes are defined and support for the change that the programme will bring about permeates the organisation.

\section{Research design Research approach}

This implementation evaluation assessed whether or not a VCT programme, consisting of three types of organised activity, was implemented as described in the programme plan. A descriptive design was utilised for this implementation fidelity evaluation.

\section{Research method}

\section{Research participants}

The VCT programme was available to all staff and students. During June-August 2009 the staff and students who made use of the VCT service were requested to complete a questionnaire. Convenience sampling was used, as completion of the questionnaire was voluntary. The final sample comprised 285 participants (281 students and 4 staff members).

\section{Measuring instruments}

The evaluators developed a questionnaire to assess the perceptions of staff and students who used the VCT service. This 35-item questionnaire was based on Tool 2, Tool 3 and Tool 4 of the UNAIDS Best Practice Collection (2000), and a questionnaire developed by the university's HIV and AIDS Institutional Co-ordination Unit (HAICU) (2008) for evaluating their HIV and AIDS programme. Section A comprised nine questions relating to a participant's demographics and included questions about gender, age, race, nationality, faculty and year of study. Section B consisted of 26 5-point Likert-type scale questions relating to a participant's perceptions of the quality, sequence and timing of the three VCT activities. The full questionnaire is available from the evaluators.

The sub-scales for the quality of pre-test counselling $(\alpha=0.867)$ and post-test counselling $(\alpha=0.869)$ of the questionnaire had a Cronbach's alpha coefficient greater than 0.8, indicating that these measures had good internal consistency (Pallant, 2007).

\section{Research procedure}

Permission to administer the questionnaire to human participants was obtained from the Research Ethics
Committee of the Faculty of Commerce. The questionnaire was administered to VCT participants at all sites between mid-June and mid-August 2009. Paper-based questionnaires were placed at each of the VCT sites during this period and participants were asked if they would take the time to fill in a confidential questionnaire pertaining to their experiences of the VCT service. On the front page of each questionnaire the purpose of the evaluation and the voluntary and anonymous nature of completing the questionnaire were explained. Completed questionnaires were placed in sealed boxes provided at each of the sites. The completed questionnaires were collected weekly by the first evaluator. Once collected, each of the questionnaires was given a number, checked for any missing data and coded for a specific site.

\section{Statistical analysis}

Descriptive statistics (percentages, means, standard deviations) were used to analyse the data from the questionnaires.

\section{Results}

In this section the results of the evaluation will be presented according to the evaluation questions.

\section{Service utilisation}

\section{How many students and staff made use of the VCT programme?}

A sample of 285 participants (281 students and 4 staff members) completed the questionnaire during June-August 2009. Although participants who completed the questionnaire are not a true reflection of the actual participants who used the programme, this sample approximates the best information available regarding the number of people who access the VCT programme.

\section{What were the demographic characteristics of the participants?}

In Table 1 the gender, race and age demographics, by student and staff participants, are shown.

TABLE 1: Demographics of the sample.

\begin{tabular}{|c|c|c|}
\hline \multirow[t]{2}{*}{ Demographic } & \multicolumn{2}{|c|}{$\%$} \\
\hline & Students $\hat{\dagger}$ & Staff: \\
\hline \multicolumn{3}{|l|}{ Gender } \\
\hline Male & 31.7 & 50 \\
\hline Female & 68.3 & 50 \\
\hline \multicolumn{3}{|l|}{ Race } \\
\hline Black & 35.9 & 25 \\
\hline Coloured & 15.3 & - \\
\hline Indian & 3.6 & - \\
\hline White & 22.4 & 25 \\
\hline International & 20.6 & 50 \\
\hline Prefer not to answer & 1.1 & - \\
\hline \multicolumn{3}{|l|}{ Age } \\
\hline Mean & 20.5 years & 27.8 years \\
\hline
\end{tabular}


From Table 1 it is clear that the programme was mainly used by women $(68.3 \%)$. The highest uptake was amongst Black students (35.9\%), then White students (22.4\%) and international $(20.6 \%)$ students. Student participants had a mean age of 20.5 years.

The majority of student participants were in their first (32.7\%) or second (25.3\%) year of study. Few responses were obtained from postgraduate students $(n=28 ; 10 \%)$. There was a low rate of uptake amongst staff (only four made use of the services offered by the 2009 VCT drive). Of the student respondents, the majority were registered in the largest faculties, namely Humanities (34.4\%) and Commerce (29.1\%). Based on the number of responses obtained from each of the VCT sites, it appears that most participants $(94.7 \%)$ made use of the VCT Drive as opposed to other sites. Of the participants $26 \%$ were first time testers, whilst $44.2 \%$ indicated that they had been tested in the six months prior to the evaluation.

\section{Service delivery}

\section{Where did the participants hear about the programme?}

Table 2 shows how respondents became aware of the VCT programme.

Advertising seemed to be the most effective means of marketing the VCT programme on campus. Word of mouth also appeared to play a significant role to encourage participants to make use of VCT.

\section{What was the actual sequence of programme activities and did all participants receive the activities in the same sequence?}

All participants (100\%) experienced the same sequence of activities across all four of the VCT sites. The sequence was pre-test counselling, followed by a Rapid HIV test and, finally, post-test counselling.

Was the programme delivered in the same manner across all VCT sites in terms of the quality of pre-test counselling, HIV testing and post-test counselling?

Pre-test Counselling: The mean scores and standard deviations for the seven pre-test items were combined and are presented in Table 3.

From these results, it was evident that the quality of pretest counselling differed slightly across the four VCT sites. However, the lowest of these mean scores still ranked on the higher end of the 5-point scale, indicating that standards of pre-test counselling ranged between good to excellent across all VCT sites.

The Rapid HIV test: The participants' opinions relating to the professionals who performed the Rapid HIV test are presented in Table 4.

Approximately two thirds of the participants were unsure whether or not the test was performed by a nurse or a medical practitioner.
TABLE 2: How respondents became aware of the VCT programme.

\begin{tabular}{ll}
\hline Awareness of VCT on Campus & $\%$ \\
\hline Advertising on campus & 63.2 \\
Referred by a friend & 15.1 \\
Combination of advertising and referral & 14.0 \\
Community Aids Educators (ACE's) & 1.1 \\
UCT Treatment Action Campaign (TAC) organisation & 1.1 \\
\hline
\end{tabular}

TABLE 3: Mean scores and standard deviations for the quality of pre-test counselling for each of the VCT sites.

\begin{tabular}{lll}
\hline VCT Site & Mean & Standard deviation \\
\hline Site 1 & 4.43 & 0.371 \\
Mobile Bus & 4.29 & 0.202 \\
VCT Drive & 4.05 & 0.733 \\
Site 2 & 3.96 & 0.317 \\
\hline
\end{tabular}

Note: For each item, Minimum $=1$ and Maximum $=5$.

TABLE 4: Respondents' opinions relating to whom performed their Rapid HIV test.

\begin{tabular}{lcccc}
\hline Rapid HIV Test performed by a & \multicolumn{4}{c}{$\%$} \\
\cline { 2 - 5 } Nurse or Medical Practitioner & VCT Drive & Site 1 & Site 2 & Mobile Bus \\
\hline Yes & 34.1 & 77.8 & 100 & 100 \\
Unsure & 64.8 & - & - & - \\
No & 1.1 & 22.2 & - & - \\
\hline
\end{tabular}

TABLE 5: Mean scores and standard deviations for the quality of post-test counselling for each of the VCT sites.

\begin{tabular}{lll}
\hline VCT site & Mean & Standard deviation \\
\hline Mobile Bus & 4.88 & 0.177 \\
VCT Drive & 4.59 & 0.567 \\
Site 1 & 4.44 & 0.391 \\
Site 2 & 4.06 & 0.125 \\
\hline
\end{tabular}

Note: For each item, Minimum $=1$ and Maximum $=5$.

Post-test Counselling: Table 5 presents the combined means and standard deviations for the four post-test counselling quality items.

Mean scores for the post-test counselling quality ranged from 4.06 (Site 2) to 4.88 (Mobile Bus) on a 5-point scale. This indicated that standards of post-test counselling were good to excellent across all four VCT sites.

\section{Were participants satisfied with the service they received from the VCT programme?}

The participants' ratings of their overall VCT experience are presented in Table 6.

Based on these results, it can be concluded that participants were satisfied to highly satisfied with the level of service they received on the programme.

\section{Organisational support}

Was the VCT programme well organised, with specific focus on how long participants waited to receive the results from their HIV test?

Five participants were unable to provide an estimate of how long it took to receive the results and were excluded from the calculation for the average waiting time. In Table 7 the average time it took to obtain the test results is presented. 
Pre-test counselling on the Mobile Bus was brief in comparison with the other VCT sites, as the two participants were from the medical faculty and they might have opted not to receive in depth pre-test counselling because of existing knowledge of HIV.

\section{Were the participants receiving the dosage, type and quality of counselling as stipulated in the VCT programme protocol documentation?}

Out of the 285 respondents, 283 indicated that they had received an HIV negative test result whilst the remaining two respondents had tested HIV positive. The majority of HIV negative respondents $(57.2 \%)$ reported that they strongly agreed with the statement that the post-test counsellor had reinforced strategies for reducing the risk of contracting HIV. Most of these HIV negative respondents (66.1\%) also indicated that the post-test counsellor clearly discussed their understanding of the window period relating to HIV infection.

The two HIV positive respondents strongly agreed that the implications of an HIV positive result were clearly and simply discussed with them, that the counsellor had discussed their personal risk reduction plan and that referrals in relation to medical, social and psychological support were offered. Whilst the one respondent strongly agreed with the statement that the counsellor had offered follow-up support, the other disagreed. When asked whether or not immediate plans and intentions had been explored by the counsellor, one participant strongly agreed and one disagreed.

\section{Discussion}

The main objective of the evaluation was to determine whether or not a VCT programme for HIV and AIDS at a South African university was implemented as intended. The importance of the evaluation lies in the three main recommendations regarding:

- uptake of the VCT programme amongst men

- identification of the professional status of the programme staff who perform the tests

- shortening the waiting period for test results.

Should these recommendations be implemented, the programme would be implemented as intended.

In summary, the results indicated that the VCT programme was delivering a quality service and was operating as intended. Therefore, the programme could be judged as having high implementation fidelity. These results will be discussed in more detail and according to the three standard aspects of an implementation evaluation, namely service utilisation, service delivery and organisational support.

\section{Service utilisation}

When examining utilisation, the 285 participants in the 2009 evaluation need to be viewed against annual numbers for earlier uptake. In 2008, 5209 participants made use of the programme whilst between February and October 2009,
TABLE 6: Respondents' ratings of their overall VCT experience.

\begin{tabular}{lccccc}
\hline Site & \multicolumn{5}{c}{$\%$} \\
\cline { 2 - 6 } & Excellent & Good & Average & $\begin{array}{c}\text { Slightly } \\
\text { disappointed }\end{array}$ & Disappointed \\
\hline Mobile Bus & 100.0 & - & - & - & - \\
Site 1 & 62.5 & 37.5 & - & - & - \\
VCT Drive & 61.7 & 35.3 & 3.9 & 0.7 & - \\
Site 2 & 50.0 & 50.0 & - & - & - \\
\hline
\end{tabular}

TABLE 7: Average timeframe, in minutes, for pre-test counselling, post-test counselling and waiting period for test results.

\begin{tabular}{lllll}
\hline Testing stage & Site $\mathbf{1}$ & Site $\mathbf{2}$ & Mobile bus & VCT Drive \\
\hline Pre-test & 30.00 & 7.24 & 3.30 & 6.29 \\
Post-test & 7.45 & 4.38 & 6.00 & 4.38 \\
Result & 15.00 & 7.53 & 4.30 & 14.05 \\
\hline
\end{tabular}

5114 participants used it. In terms of student numbers, the university is a medium-sized institution with approximately 24000 students. Utilisation figures suggest an uptake percentage of approximately $21 \%$ per year. It could be assumed that this percentage covers most of the new undergraduate intake in the university. It is clear that staff members did not utilise the VCT services. Whilst academic and administrative staff may have a testing service available via their medical aid, outsourced service staff have no medical aid policies. The programme managers may want to include this particular group of staff in their target population in future.

The programme is predominantly being used by women. This supports the findings of previous studies on VCT uptake (Bond et al., 2005; Bwambale et al., 2008; Fako, 2006; Pronyk et al., 2002; Subramanian et al., 2008) which have shown that men are less likely to make use of VCT compared with women. Few of these studies attempt to present methods for overcoming this gender bias, which indicates that there is a gap in the literature when it comes to improving VCT uptake amongst men.

In order to increase the number of male participants in the programme, the evaluators suggest that a mass communication campaign, targeting men, is utilised. Mass communication programmes are effective in making individuals aware of HIV prevention programmes or to increase their knowledge of HIV (Charles et al., 2009; USAID, 2009). Furthermore, exposure to mass communication programmes have been associated with increased uptake of VCT programmes, increased HIV knowledge and a reduction in high-risk sexual behaviour (Bertrand, O'Reilly, Denison, Anhang \& Sweat, 2006; Marum, Morgan, Hightower, Ngare \& Taegtmeyer, 2008). Mass communication campaigns are believed to be most effective in terms of sustaining behaviour change when their messages are reinforced on a continuous basis (USAID, 2009). The VCT programme should, therefore, consider using different media (pamphlets, posters, student radio, music concerts and social networking tools like Twitter). Competitions could also be run in conjunction with the mass communication campaign. These competitions could provide desirable age and gender appropriate 
prizes on a lucky draw basis to VCT participants. Another reinforcing strategy could be to provide educational HIV and AIDS programmes as part of the students' study curriculum. Education is often used as a means to increase HIV and AIDS awareness and reduce the stigma associated with the disease (Ho \& Loke, 2003; Okonkwo et al., 2007). One must, however, bear in mind that increasing HIV awareness alone will not always result in an individual choosing to get tested for HIV (Fako, 2006).

The Student Wellness Centre could consider offering students a package of medical services in an attempt to overcome the stigma associated with HIV. This package could include VCT, a cholesterol test, a blood glucose test and a calculation of Body Mass Index (BMI). Incorporating VCT into a package of health services may reduce the fear of HIV-related stigma as students and staff will begin to perceive VCT as a standard component of a wellness programme.

In terms of race demographics, White students are the numerical majority at this university, but showed lower uptake of the programme than Black students. The small percentage of Coloured and Indian students is expected, as they account respectively for $15 \%$ and $7 \%$ of the university population.

The age range of the sample represents the dominant age cohort at universities. Furthermore, this cohort tends to be most susceptible to contracting HIV and AIDS (Njagi \& Maharaj, 2006; Steinberg et al., 2001; UNAIDS, 2004). It can, therefore, be said that this VCT service is reaching one of its intended targets, namely students.

Undergraduate students showed significantly higher uptake than postgraduate students. The low response rate from postgraduate students could be a result of the fact that a number of postgraduate courses are offered after hours and that the VCT programme only operates during working hours. Few staff members made use of the VCT service. This could be contributed to concerns regarding anonymity, especially during VCT Drives when participants queue in public to be tested (Hutchinson \& Mahlalela, 2006; Matovu \& Makumbi, 2007; Wringe et al., 2008). Also, staff may choose to make use of private testing, as offered by their medical aid. Based on these results the programme managers may want to revise the target population of the VCT service to all students only.

Of the student respondents, the majority were registered in the largest faculties, namely Humanities and Commerce. These faculties are located on the main campus and students, therefore, have easy access to the VCT services. No responses were obtained from students or staff from the Graduate School of Business which is located approximately ten kilometres away from the main campus. Based on the number of responses obtained from each of the VCT sites, it appears that most participants $(94.7 \%)$ made use of the VCT drive on the main campus as opposed to other sites. This is in line with research findings which showed that offering HIV testing at a convenient and accessible location usually results in a higher uptake of the programme (Bhagwanjee, et al., 2008; Bond et al., 2005; Corbett et al., 2006; Hutchinson \& Mahlalela, 2006; Irungu et al., 2008).

There were more regular testers than first time testers in the sample. These results may indicate that it is socially acceptable for students to know their HIV status. The majority (98.2\%) of participants confirmed this, by indicating that it was important to know one's HIV status. This finding is supported by Subramanian et al. (2008) and Irungu et al. (2008) who indicated that the most common reason for a participant's willingness to be tested was that it was important to know one's status for protection of oneself and others.

In summary, the VCT programme is reaching its intended young, undergraduate, student population, specifically during VCT Drives on Site 1. It remains problematic that women are using the programme more than men. Staff are poor users of the programme, but may utilise other means and sites to obtain their HIV status. It is encouraging that the majority of participants indicated that it is important to know one's HIV status. However, at this stage we do not know whether or not non-participants also think that it is important to know their status.

\section{Service delivery}

Advertising seems to be the most effective means of marketing the VCT programme on campus. Word of mouth also appears to play a significant role to encourage participants to make use of VCT. However, the crucial question is: why do advertising and word of mouth lead to utilisation by women, but not by men?

All participants experienced the intended sequence of services (Coetzee \& Patel, 2000) across all the VCT sites. It could be concluded that, as far as sequencing of programme activities is concerned, the programme is delivered with fidelity. This result, regarding the fidelity of the VCT programme, is important, as Bhagwanjee et al. (2008) and Mundy and Dickinson (2004) pointed out that programme success is dependent on specific implementation protocols.

The quality of pre-test counselling showed slight differences across sites, but was generally ranked positively. As regards the Rapid HIV test, two thirds of the participants were unsure about the professional status of the person performing the test. This is problematic. According to the programme description, the Rapid HIV test can only be performed by a nurse or a medical practitioner (Coetzee \& Patel, 2000). Informing the participants that their Rapid HIV test is being performed by a nurse or medical practitioner may increase the credibility of the VCT service. It may also reduce any concerns they may have about whether or not the correct protocols are being followed in relation to the Rapid HIV test. Participants rated the quality of the post-test counselling 
across all four sites positively. According to Day et al. (2003) and UNFPA (2002) the fidelity of this step is crucial as it provides participants with risk reduction strategies.

The service delivery of the programme conforms to the standards of good practice and participant satisfaction. However, participants need to be informed that the required professionals are doing the HIV test, as this may lend more credibility to the programme.

\section{Organisational support}

The waiting time to receive one's HIV result is much longer at the VCT Drive on the main campus compared with the Mobile Bus and Site 1. This could be a result of the high uptake during the VCT Drive and the practice of three different programme staff performing the three respective programme activities. At other sites, there is a lower uptake and one individual performs all three activities. Rapid feedback of test results is necessary for the success of the VCT programme (Bhagwanjee et al., 2008; Mundy \& Dickinson, 2004). The evaluators suggest that more staff should be appointed during the VCT Drive in order to conform to VCT protocol standards for rapid feedback.

HIV negative participants found the counselling informative and rated it as positive. The two HIV positive participants agreed that the implications of their status were made clear to them. However, one of the latter participants indicated that follow-up support was not discussed satisfactorily. This left the participant unsure about the immediate next steps. Despite only one HIV positive participant reporting this, it is suggested that the programme staff focus specifically on this issue when counselling HIV positive students. According to Coetzee and Patel (2000), Ginwalla et al. (2002), McCauley (2004) and Wringe et al. (2008) the fidelity of post-test counselling is important. The reason for its importance is that it provides information on disclosure, partner referral, identification of support and medical services and a risk reduction plan to those who test negative.

Finally, it should be noted that the majority of the participants in the current evaluation were HIV negative. Between February and October 2009 only 13 HIV positive results had been obtained across all VCT sites at this university (Dr C. Landon, personal communication, 20 November 2009). The low prevalence of HIV and AIDS at this Western Cape University was highlighted by the HEAIDS (2010) study. Concerning infection, this study found academics showed $0.2 \%$ prevalence, students $1.1 \%$, administrative staff $0.9 \%$ and service staff $1.2 \%$. It is, therefore, suggested that the university follows the strategy of 'no new infections' and focuses on drawing more participants, especially male participants, into its existing VCT programme.

\section{Limitations of the evaluation}

The evaluators were reliant on VCT programme staff to promote the questionnaire at most of the sites. This did not happen in a systematic manner. Also, data collection on Sites 1, 2 and the Mobile Bus took place during the June vacation and may have influenced response rates.

\section{Suggestions for future evaluations}

Firstly, changes should be implemented to attract more men to the programme. Secondly, future evaluations could focus on whether or not the mass communication strategies of the programme worked. Thirdly, a study with a quasiexperimental design (those who made use of the programme and those who did not), which focuses on the programme's outcomes as dependent variables, could provide the programme managers with useful information about the participants' attitudes to the programme and its uptake.

\section{Acknowledgements Competing interests}

The authors declare that they have no financial or personal relationship(s) which may have inappropriately influenced them in writing this paper.

\section{Authors' contributions}

T.N.A. (University of Cape Town) completed this evaluation as a requirement for her Master's degree in Programme Evaluation. J.L.-P. (University of Cape Town) supervised the evaluation.

\section{References}

Bhagwanjee, A., Petersen, I., Akintola, O., \& George, G. (2008). Bridging the gap between VCT and HIV/AIDS treatment uptake: Perspectives from a mining-sector workplace in South Africa. African Journal of AIDS Research, 7(3), 271-279. http:// dx.doi.org/10.2989/AJAR.2008.7.3.4.651

Bickman, L. (1987). The functions of program theory. New Directions for Program Evaluation, 33, 5-18. http://dx.doi.org/10.1002/ev.1443

Bertrand, J.T., O'Reilly, K.O., Denison, J., Anhang, R., \& Sweat, M. (2006). Systematic review of the effectiveness of mass media communication programs to change HIV/AIDS-related behaviours in developing countries. Health Education Research, 21(4), 567-597. http://dx.doi.org/10.1093/her/cyl036, PMid:16847044

Bond, L., Lauby, J., \& Batson, H. (2005). HIV testing and the role of individual and structural level barriers and facilitators. AIDS Care, 17(2), 125-140. http://dx.doi. org/10.1080/09541020512331325653, PMid:15763709

Bwambale, F.M., Ssali, S.N., Byaruhanga, S., Kalyango, J.N., \& Karamagi, C.A. (2008). Voluntary HIV counselling and testing among men in rural western Uganda: Implications for HIV prevention. Bio-Medical Central Public Health, 8, 263-276.

Centre for Human Development. (2002). HIV/AIDS training manual. Retrieved from the archives of the VCT Programme, University of Cape Town.

Charles, M.P., Kweka, E.J., Mahande, A.M., Barongo, L., Shekalaghe, S., Nkaya, H., et al. (2009). Evaluation of uptake and attitude to voluntary counselling and testing among health care professional students in Kilimanjaro region, Tanzania. BioMedical Central Public Health, 9(128), 1-9.

Chen, H. (2005). Practical program evaluation: Assessing and improving planning, implementation and effectiveness. Thousand Oaks: Sage Publications.

Coetzee, N., \& Patel, B. (2000). Protocol document: Voluntary counselling and testing. Western Cape: Department of Health.

Corbett, E.L., Dauya, E., Matambo, R., Chengi, Y.B., Makamure, Bassett, T., et al. (2006). Uptake of workplace HIV counselling and testing: A cluster-randomised trial in Zimbabwe. Plos Medicine, 3(7), 1005-1012. http://dx.doi.org/10.1371/ journal.pmed.0030238, PMid:16796402.

Davidson, T. (n.d.). HIV/AIDS issues at UCT. Retrieved from the archives of the VCT Programme, University of Cape Town.

Day, J.H., Miyamura, K., Grant, A.D., Leeuw, A., Munsamy, J., Baggaley, R., et al. (2003) Attitudes to HIV voluntary counselling and testing among mineworkers in South Africa: Will availability of antiretroviral therapy encourage testing? Aids Care, 15 665-672. http://dx.doi.org/10.1080/0954012030001595140, PMid:12959817

Donaldson, S.I. (2007). Program theory-driven evaluation science: Strategies and applications. New York: Lawrence Erlbaum Associates. 
Donaldson, S.I., \& Lipsey, M.W. (2006). Roles for theory in contemporary evaluation practice: Developing practical knowledge. In I. Shaw, J.C. Greene, \& M.M. Mark (Eds.), The handbook of evaluation: Policies, programs and practices, (pp. 56-75). (Eds.), The handon: Sage.

Fako, T.T. (2006). Social and psychological factors associated with willingness to test for HIV infection among young people in Botswana. Aids Care, 18, 201-207. http://dx.doi.org/10.1080/09540120500456623, PMid:16546779

Family Health International. (2003). VCT toolkit. Retrieved from the archives of the VCT Programme, University of Cape Town.

Fishbein, M., \& Ajzen, I. (1980). Understanding attitudes and predicting socia behavior. New York: Prentice Hall.

Ginwalla, S.K., Grant, A.D., Day, J.H., Dlova, T.W., Macintyre, S., Baggaley, R., et al. (2002). Use of UNAIDS tools to evaluate HIV voluntary counseling and testing services for mineworkers in South Africa. Aids Care, 14, 707-726. http://dx.doi.o g/10.1080/0954012021000005533, PMid:12419119

Greiger, I., \& Ponterotto, J.G. (1988). Student's knowledge of AIDS and their attitudes towards gay men and lesbian woman. Journal of College Student Development towards gay

HAICU. (2008). Responses to HIV and AIDS at UCT: Report to Council. Retrieved November 12,2009, from http://www.uct.ac.za/downloads/uct.ac.za/about/ November 12, 2009, from http://WwW.
introducing/aids/aids_councilreport07.pdf

HEAIDS. (2010). HIV prevalence and related factors - Higher Education Sector Study, South Africa, 2008-2009. Pretoria: Higher Education South Africa.

Ho, C.F., \& Loke, A.Y. (2003). HIV/AIDS knowledge and risk behavior in Hong Kong Chinese pregnant women. Journal of Advanced Nursing, 43, 238-245. http:// dx.doi.org/10.1046/j.1365-2648.2003.02706.x

Hollar, D.S., \& Snizer, W.E. (1996). The influences of knowledge of HIV/AIDS and self-esteem on the sexual practices of college students. Social Behaviour and Personality, 24, 75-86. http://dx.doi.org/10.2224/sbp.1996.24.1.75

Hutchinson, P.L., \& Mahlalela, X. (2006). Utilization of voluntary counselling and testing services in the Eastern Cape, South Africa. Aids Care, 18, 446-455. http:// dx.doi.org/10.1080/09540120500213511, PMid:16777636

Inverness Medical. (2009). Product specifications. Retrieved April 21, 2009, from http://www.determinetest.com/hiv_1/2/product_specifications.aspx

Irungu, T.K., Varkey, P., Cha, S., \& Patterson, J.M. (2008). HIV voluntary counselling and testing in Nakuru, Kenya: Findings from a community survey. 111-117. http://dx.doi.org/10.1111/j.1468-1293.2007.00538 x, PMid:18257773

Kachroo, S. (2006). Promoting self-testing for HIV in developing countries: Potential benefits and pitfalls. Bulletin of the World Health Organization, 84(12), 999-1000. http://dx.doi.org/10.2471/BLT.06.032656, PMid:17242837, PMCid:2627574

Keeling, P.R. (1991). Time to move forward: An agenda for campus sexual health promotion in the next decade. Journal of American College Health, 40, 51-53. http://dx.doi.org/10.1080/07448481.1991.9936256, PMid:1939934

Landon, C. (2007). Statistics relating to VCT testing at UCT. Unpublished raw data.

Landon, C. (2008). Statistics relating to VCT testing at UCT. Unpublished raw data.

Landon, C. (2009). Statistics relating to VCT testing at UCT. Unpublished raw data.

Lema, L.A., Katapa, R.S., \& Musa, A.S. (2008). Knowledge on HIV/AIDS and sexual behaviour among youths in Kibhala District, Tanzania. Journal of Health Research, $10,79-83$.

Louw, J. (in progress). Programme evaluation: Can it improve human resource management practice? South Journal for Human Resource Management. Manuscript submitted for publication.

Mabunda, G. (2004). HIV knowledge and practices among rural South Africans. Journal of Nursing Scholarship, 36, 300-304. http://dx.doi.org/10.1111/j.15475069.2004.04055.x, PMid:15636408

Marum, E., Morgan, G., Hightower, A., Ngare, C., \& Taegtmeyer, M. (2008). Using mass media campaigns to promote voluntary counseling and testing services in Kenya. AIDS, 22(15), 2019-2025. http://dx.doi.org/10.1097/QAD.0b013e3283104066, AlDS, 22(15), 2016
PMid:18784464

Matovu, J.K., \& Makumbi, F.E. (2007). Expanding access to voluntary HIV counseling and testing in sub-Saharan Africa: Alternative approaches for improving uptake. Tropical Medicine and International Health, 12, 1315-1322. http://dx.doi. Tropical Medicine and International

McCauley, A.P. (2004). Equitable access to HIV counselling and testing for youth in developing countries: A review of current practice. Retrieved November 20, 2009, from http://www.popcouncil.org/horizons.html
Mundy, J., \& Dickinson, D. (2004, June). Factors affecting the uptake of voluntary HIV/ AIDS counselling and testing (VCT) services in the workplace. Paper presented at the Wits HIV/AIDS in the Workplace Symposium, Wits University, Johannesburg.

Njagi, F., \& Maharaj, P. (2006). Access to voluntary counselling and testing services: Perceptions of young people. South Africa Review of Sociology, 37(2), 113-127. http://dx.doi.org/10.1080/21528586.2006.10419150

Okonkwo, K.C., Reich, K., Alabi, A., Umeike, N., \& Nachman, S. (2007). An evaluation of awareness: Attitudes and beliefs of pregnant Nigerian woman toward voluntary counselling and testing for HIV. Aids Patient Care and STD's, 21(4), 252-260. http://dx.doi.org/10.1089/apc.2006.0065, PMid:17461720

Patton, M.Q. (2008). Utilization-focused evaluation. Los Angeles: Sage.

Pallant, J. (2007). SPSS survival manual: A step by step guide to data analysis using SPSS for windows. (3rd edn.). New York: Open University Press.

Peltzer, K., Nwezi, E., \& Mohan, K. (2004). Attitudes towards HIV-antibody testing and people with AIDS among university students in India, South Africa and United States. Indian Journal of Medical Sciences, 58, 95-108. PMid:15051904

Philips, K.A., Coates, T.J., Eversley, R.B., \& Catania, J.A. (1995). Who plans to be tested for HIV or would get tested if no one could find out the results? American Journal of Preventative Medicine, 11, 156-162. PMid:7662394

Pronyk, P.M., Kim, J.C., Makhubele, M.B., Hargreaves, J.R., Mohlala, R., \& Hausler, H.P. (2002). Introduction of voluntary counselling and rapid testing for HIV in rura South Africa: From theory to practice. AIDS Care, 14(6), 859-865. http://dx doi.or $\mathrm{g} / 10.1080 / 0954012021000031921$, PMid:12511218

Richter, L.M., Van Rooyen, H., Solomon, V., Griesel, D., \& Durrheim, K. (2001). Putting HIV/AIDS counselling in South Africa in its place. Society in Transition, 32(1), 148154

Rossi, P.H., Lipsey, M.W., \& Freeman, H.E. (2004). Evaluation: A systematic approach (7th edn.). California: Sage Publications.

Scheirer, M.A. (1994). Designing and using process evaluation. In J.S. Wholey, H.P. Hatry, \& K.E. Newcomer (Eds.), Handbook or practical program evaluation, (pp. 40-68). San Francisc: Jossey-Bass.

Smuts, B. (2000). Protocol for HIV Rapid Tests. Retrieved from the archives of the VCT Programme, University of Cape Town.

Standton, B.F., Xiaoming, L., Kahihuata, J., Fitzgerald, A.M., Neumbo, S., Terreri, N., et al. (1998). Increased protected sex and abstinence among Namibian youth following a HIV risk-reduction intervention: A randomised, longitudinal study. Aids, 12, 2473-2480. http://dx.doi.org/10.1097/00002030-199818000-00017, PMid:9875586

Steinberg, M., \& Kinghorn, A., Sonderlud, N., Schierhout, G., \& Conway, S. (2001). HIV/ AIDS: Facts, figures and the future. In South African Health Review (pp. 301-326). Durban: Health Systems Trust.

Subramanian, Y., Gupte, M.D., Mathai, A.K., Boopathi, K., \& Dorairaj, V.S. (2008) Perception of HIV among attendees at an STD clinic in India, Aids Care, 20(1) 26-34. http://dx.doi.org/10.1080/09540120701427480, PMid:18278612

UNAIDS. (2000). Best practice collection: Tools for evaluating HIV voluntary counseling and testing. Retrieved March 13, 2009, from http://data.unaids.org/Publications/ IRC-pub02/JC685-Tools\%20for\%20Eval_en.pdf

UNAIDS. (2004). Report on the global AIDS epidemic. Retrieved March 05, 2009, from http://www.unaids.org/bangkok2004/GAR2004_html/GAR2004_00_en.|tm

UNFPA. (2002). HIV prevention now: Voluntary counselling and testing (VCT) for HIV prevention. Retrieved March 12, 2009, from http://www.unfpa.org/hiv/ prevention/documents/hivprev5.pdf

USAID. (2009). HIV prevention knowledge base: Behavioural interventions mass media and HIV prevention. Retrieved November 15, 2009, from http://www.aidstarone. com/focus_areas/prevention/prevention_resources/behavioral_interventions/ mass_media_and_hiv_prevention

Van de Perre, P. (2000). Commentary: HIV voluntary counselling and testing in community health services. The Lancet, 356, 86-87. http://dx.doi.org/10.1016/ S0140-6736(00)02462-4

Van Dyk, A.C., \& Van Dyk, P.J. (2003). What is the point of knowing: Psychological barriers to HIV/AIDS voluntary counselling and testing programmes in South Africa. South African Journal of Psychology, 33(2), 118-125.

Wringe, A., Isingo, R., Urassa, M., Maiseli, G., Manyalla, R., Changalucha, J., et al (2008). Uptake of HIV voluntary counselling and testing services in rural Tanzania: Implications for effective HIV prevention and equitable access to treatment. Tropical Medicine and International Health, 13(3), 319-327. http://dx.doi. org/10.1111/j.1365-3156.2008.02005.x 